\title{
Triple-phase Separation of Alkaline Earth Metal Ions
}

\author{
Yu KOMATSUa and Shigeo UMETANIb
}

a National Institute for Research in Inorganic Materials 1-1 Namiki, Tsukuba, Ibaraki,305 Japan
b Institute for Chemical Research, Kyoto University, Uji, Kyoto 611, Japan

Both $\mathrm{Sr}^{2+}$ and $\mathrm{Cs}^{+}$have been acknowledged as serious components of high level radioactive waste. The separation of $\mathrm{Cs}^{+}$from solutions containing other alkali metal ions has already been accomplished by ion-exchange method using dihydrogen tetratitanate hydrate fibers. The separation of $\mathrm{Sr}^{2+}$ from other alkaline earth metal ions, however, is complicated because $\mathrm{Sr}^{2+}$ is in the middle of the selectivity series of any known separation method involving either solvent-extraction and ion-exchange methods. Separation of alkaline earth metal ions was studied by a triple-phase separation method which combined ion-exchange and solvent-extraction methods. In this study, the complete separation of individual alkaline earth metal ion has been sought for an aqueous solution containing $\mathrm{Mg}^{2+}, \mathrm{Ca}^{2+}, \mathrm{Sr}^{2+}$ and $\mathrm{Ba}^{2+}$. The selectivity series of the ion-exchange system using dihydrogen tetratitanate hydrate fibers was $\mathrm{Ba}^{2+}$ $\gg \mathrm{Sr}^{2+}>\mathrm{Ca}^{2+} \gg \mathrm{Mg}^{2+}$. $\mathrm{Ba}^{2+}$ and $\mathrm{Mg}^{2+}$ can be separated from other alkaline earth metal ions because of the large separation factors to neighboring ions, but $\mathrm{Sr}^{2+}$ and $\mathrm{Ca}^{2+}$ cannot be separated each other in this manner. The extractability of alkaline earth metal ions with the solvent extraction system using thenoyltrifluoroacetylacetone (TTA, extractant) is $\mathrm{Mg}^{2+}>\mathrm{Ca}^{2+}>\mathrm{Sr}^{2+}>\mathrm{Ba}^{2+}$. Although the separation between $\mathrm{Sr}^{2+}$ and $\mathrm{Ca}^{2+}$ is better than that by the ion-exchange method, it is not sufficient for complete separation. To accomplish complete separation of $\mathrm{Sr}^{2+}$ and $\mathrm{Ca}^{2+}$, the organic phase containing TTA was added to the ion-exchange system. Because of their reverse relationship of the selectivity series, the smaller metal ions in an aqueous phase were extracted into the organic phase, while the larger metal ions were sorbed onto the ion exchanger. The separation factors of metal ions are much larger than those obtained by solvent extraction and ion exchange methods used separately.

Keywords Solvent extraction, ion exchange, triple phase separation, alkaline earth metal ions, thenoyltrifluoroacetylacetone, dihydrogen tetratitanate hydrate

The separation of alkaline earth metal ions have been studied by solvent-extraction and ionexchange methods. The extractants, such as trifluoroacetylacetone(TTA), 1,2 tributyl phosphate (TBP) ${ }^{3}$ and Isopropyl tropolone(IPT), 4 were used to extract alkaline earth metal ions by solvent extraction method. Antimonate, 5 zirconium phosphate 6 and dihydrogen tetratitanate hydrate fibers 7 were also used to exchange these metal ions by ion exchange method. The separation of $\mathrm{Sr}^{2+}$ from other alkaline earth metal ions is much more difficult and all of the known solvent extraction and ion exchange methods have not been successful. This is primarily because $\mathrm{Sr}^{2+}$ is in the middle of selectivity series and alkaline earth metal groups. In the present study, the complete separation of $\mathrm{Sr}^{2+}$ has been investigated for an aqueous solution containing $\mathrm{Mg}^{2+}, \mathrm{Ca}^{2+}, \mathrm{Sr}^{2+}$ and $\mathrm{Ba}^{2+}$ by triple phase separation method together with solvent extraction and ion exchange methods. $\mathrm{Ba}^{2+}$ and $\mathrm{Mg}^{2+}$ can be easily separated because of their large separation factors to neighbouring ions and a triple phase system consisting of an ion exchange material, an aqueous phase and an organic solution was used to partition $\mathrm{Ca}^{2}+$ into the organic phase and $\mathrm{Sr}^{2+}$ into the ion exchange materials. This technique gives a unique method of separating difficult elements.

\section{Experimental}

\section{Chemicals}

TTA and TOPO were obtained from Dojindo Laboratories. Titanium dioxide used was of $99.9 \%$ purity. All the other reagents were of analytical grade. Distilled and deionized water was used throughout the experiments. The aqueous 
standard solutions of alkaline earth metal ions $\left(\mathrm{Ba}^{2+}, \mathrm{Sr}^{2+}, \mathrm{Ca}^{2+}\right.$ and $\mathrm{Mg}^{2+}$ ) were prepared by dissolving corresponding chloride salts in water. Layered potassium tetratitanate fibers, $\mathrm{K}_{2} \mathrm{Ti}_{4} \mathrm{O}_{9}$ were first synthesized 8 by slow cooling of a $\mathrm{K}_{2} \mathrm{MoO}_{4}$ flux melt containing $\mathrm{K}_{2} \mathrm{CO}_{3}$ and $\mathrm{TiO}_{2}(1: 3$ molar ratio). After melting the mixtures at $1423 \mathrm{~K}$, the melted materials were cooled to $1223 \mathrm{~K}$ (cooling rate: $4 \mathrm{~K} / \mathrm{h}$ ) and fibrous crystals of $\mathrm{K}_{2} \mathrm{Ti}_{4} \mathrm{O}_{9}$ were obtained. About $15 \mathrm{~g}$ portion of the fibers was filled in a glass column with an inner diameter of $25 \mathrm{~mm}$. The fibers were washed with about $20 \mathrm{dm}^{3}$ of water to remove residual $\mathrm{K}_{2} \mathrm{MoO}_{4}$. Subsequently, $1 \mathrm{~mol} \mathrm{dm}^{-3}$ hydrochloric acid solution was passes through the column to convert $\mathrm{K}_{2} \mathrm{Ti}_{4} \mathrm{O}_{9}$ into a $\mathrm{H}$ form according to the following reaction. The flow rate is $1 \mathrm{dm}^{3} /$ day.

$\mathrm{K}_{2} \mathrm{Ti}_{4} \mathrm{O}_{9}+\mathrm{nH}_{2} \mathrm{O} \leftrightarrows \mathrm{H}_{2} \mathrm{Ti}_{4} \mathrm{O}_{9} \cdot \mathrm{nH}_{2} \mathrm{O}+2 \mathrm{~K}^{+}$

After the potassium ion concentration in the effluent became less than $1 \times 10^{-5} \mathrm{~mol} \mathrm{dm}^{-3}$ detected by an atomic absorption spectrophotometer, the fibers were washed with water until the $\mathrm{pH}$ value in the effluent was below 5.5 (flow rate: effluent $1 \mathrm{dm}^{3} /$ day). The solid product was stocked in a constant fumidity box controlled by a saturated $\mathrm{NaCl}$ solution (relative humidity:70\%) to keep the original amount of the interlayer water in the fibers. The fibers were 1 $\mathrm{mm}$ in length and $0.01 \mathrm{~mm}$ in diameter on average.

\section{Solvent extraction separation of metal ions}

Stoppered glass tubes of $20 \mathrm{~cm}^{3}$ were used to contact $10 \mathrm{~cm}^{3}$ of an aqueous solution and $10 \mathrm{~cm}^{3}$ of benzene containing TTA (extractant) and TOPO (adduct forming ligand). The aqueous solution contained alkaline earth metal ion in the form of chloride with the concentration of $1 \times 10^{-4} \mathrm{~mol} \mathrm{dm}^{-3}$ and acetate buffer of $5 \times 10^{-3} \mathrm{~mol} \mathrm{dm}^{-3}$. The $\mathrm{pH}$ of the aqueous solution was adjusted with perchloric acid or sodium hydroxide solution. The tubes were shaken by a mechanical shaker which was placed in the thermostated room at $298 \mathrm{~K}$. The ionic strength of the aqueous solution was controlled at $0.1 \mathrm{~mol} \mathrm{dm}^{-3}$ with sodium perchlorate. In order to know the time dependence of the extraction. reaction of alkaline earth metal ions, the experiment for each metal ion was carried out for the different duration of shaking time. The $\mathrm{pH}$ of the aqueous solution was measured after establishing the equilibration by a pH meter (model TOA, HM 60s). The metal content in the aqueous solution was determined by an atomic absorption spectrophotometer (Hitachi Zeeman Spectrophotometer, model $180-80$ ) or an inductively coupled plasma spectrophtometer (Seiko Denshi, model SPS 1100). From the analytical data, the distribution equilibria of the alkaline earth metal ions were determined at $298 \mathrm{~K}$.

\section{Ion exchange separation of metal ions}

Stoppered glass tubes as same as those for solvent extraction experiment were used to equilibrate the ion exchange reaction of alkaline earth metal ions between solid $(0.1 \mathrm{~g}$ of dihydrogen tetratitanate hydrate fibers) and aqueous solution $\left(10 \mathrm{~cm}^{3}\right)$. The initial metal chloride concentration in an aqueous solution was $1 \times 10^{-4} \mathrm{~mol} \mathrm{dm}^{-3}$ and the $\mathrm{pH}$.was adjusted with hydrochloric acid solution. The content of the tubes was agitated 100 times a day by hand for 15 days. The equilibrium of the ion exchange reaction for alkaline earth metal ions was attained within this period. After standing the tubes for one day, the materials were separated by aid of centrifugation for twenty minutes at 4000 r.p.m. The metal content in the supernatant and the $\mathrm{pH}$ were measured with the same methods for the solvent extraction experiment. The metal content in the solid phase was calculated from the initial and equilibrium concentration in the aqueous solution.

\section{Triple phase separation of metal ions}

As the ion exchange reaction takes long time to reach equilibrium, aqueous solution containing alkaline earth metal ions was firstly contacted to dihydrogen tetratitanate hydrate fibers. The organic solution containing TTA and TOPO was added to the solid-liquid system at 10 days after the contact. The triple phase mixture, organicaqueous-solid was slowly agitated for 5 days to achieve the equilibrium. Other experimental procedures were the same as theose described above.

\section{Results and discussion}

The solvent extraction of alkalien earth metal ions is expressed in terms of the distribution ratio, D:

$\mathrm{D}=\mathrm{CM}_{(\mathrm{o})} / \mathrm{CM}$

where $\mathrm{C}$ represents the total concentration and the subscript "o" denotes the organic solution.

Figure 1 gives the $\log \mathrm{D}$ values as a function of $\mathrm{pH}$ in the aqueous phase. The $\log \mathrm{D}$ is proportional to the $\mathrm{pH}$ of the aqueous solution under the constant concentration of the hydrogenion in the organic phase. The slopes of the linear relations shown in Fig. 1 were close to +2 and it is reported that two TOPOs were attached to one metal ion in the previous results. 7 This indicates that the solvent extraction reaction of alkaline earth metal ions can be written as follows. 


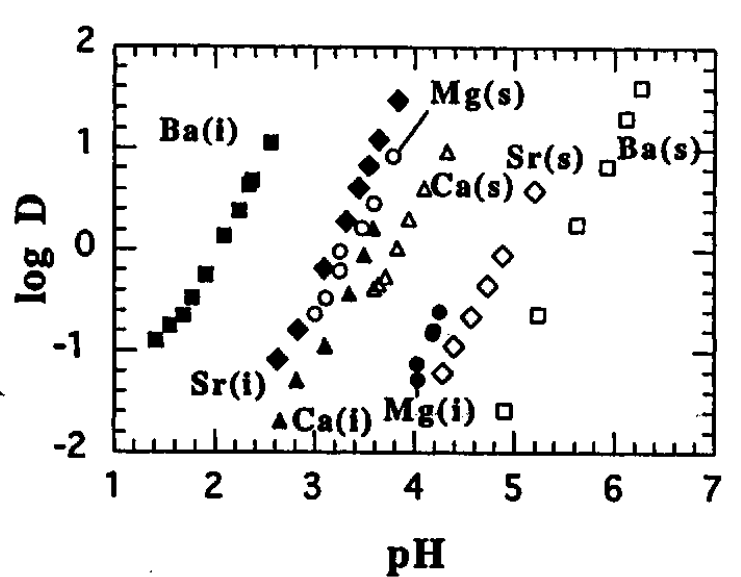

Figure 1 Solvent extraction of alkaline earth metal ions into benzene with TTA $\left(0.1 \mathrm{~mol} \mathrm{dm}^{-3}\right)$ and TOPO ( $0.1 \mathrm{~mol} \mathrm{dm}^{-3}$ ) (open symbols).

Ion exchange of alkaline earth metal ions in the aqueous solution $\left(10 \mathrm{~cm}^{3}\right)$ onto dihydrogen tetratitanate hydrate fibers $(0.1 \mathrm{~g})$ (closed symbols).

$$
\begin{aligned}
& \mathrm{M}^{2+}+2 \mathrm{HA}_{(0)}+2 \mathrm{TOPO}_{(0)} \\
& \leftrightarrows \quad \mathrm{MA}_{2}(\mathrm{TOPO})_{2(0)}+2 \mathrm{H}^{+}
\end{aligned}
$$

where HA denotes TTA and the subscript "o" represents the chamical species in the organic phase.

On the other hand, the ion exchange of alkaline earth metal ions is also expressed in terms of the distribution ratio, $\mathrm{D}$ :

$$
\mathrm{D}=\mathrm{CM}_{(\mathrm{s})} / \mathrm{CM}
$$

where $C$ represents the total concentration and the subscript " $\mathrm{s}$ " denotes the solid phase.

The $\mathrm{D}$ values were given by the deta obtained under the experimental consitions, $0.1 \mathrm{~g}$ of solid and $10 \mathrm{~cm}^{3}$ of aqueous solution.

Figure 1 also gives the $\log \mathrm{D}$ values as a function of $\mathrm{pH}$ in the aqueous solution. The $\log \mathrm{D}$ is proportional to the $\mathrm{pH}$ of the aqueous solution. As the slope of the linear relations shown in Fig. 1 were close to +2 , this indicates that ion exchange reaction of alkaline earth metal ions can be written as the following reaction.

$$
\begin{aligned}
& \mathrm{M}^{2+}+\mathrm{H}_{2} \mathrm{Ti}_{4} \mathrm{O}_{9} \cdot \mathrm{nH}_{2} \mathrm{O}_{(\mathrm{s})} \\
& \leftrightarrows \mathrm{MTi}_{4} \mathrm{O}_{9} \cdot \mathrm{nH}_{2} \mathrm{O}_{(\mathrm{s})}+2 \mathrm{H}^{+}
\end{aligned}
$$

where the subscript "s" represents the chamical species in the solid phase.
As is shown in Fig. 1, the order of extraction in the solvent extraction system is $\mathrm{Mg}^{2+}>\mathrm{Ca}^{2+}>\mathrm{Sr}^{2+}$ $>\mathrm{Ba}^{2+}$. This order is explained in terms of the solvation effect, the change density or steric effect in forming the chelating ring for the solvent extraction reaction. The order for ion exchange reaction $\left(\mathrm{Ba}^{2+}>\mathrm{Sr}^{2+}>\mathrm{Ca}^{2+}>\mathrm{Mg}^{2+}\right)$ is reverse relationship to those given by the solvent extraction method,. This selectivity series is due to the hydration energy of the alkaline earth metal ions in the aqueous solution. The $\mathrm{pH}_{1 / 2}$ values defined as $\mathrm{pH}$ at $50 \%$ solvent extraction or ion exchange states of alkaline earth metal ions are listed in Table 1.

Table 1 Summary of $\mathrm{pH}_{1 / 2}$ values and the calculated separation factors given by Fig.1.

$\mathrm{pH}_{1 / 2}$ values

\begin{tabular}{lcc} 
& Solvent extraction & Ion exchange \\
\hline $\mathrm{Ba}$ & 5.50 & 2.02 \\
$\mathrm{Sr}$ & 4.80 & 3.14 \\
$\mathrm{Ca}$ & 3.80 & 3.50 \\
$\mathrm{Mg}$ & 3.35 & 4.62
\end{tabular}

Separation Factors of alkaline earth metal ions

\begin{tabular}{lll} 
& Solvent extraction & Ion exchange \\
\hline $\mathrm{Ba}-\mathrm{Sr}$ & 25.1 & 174 \\
$\mathrm{Ba}-\mathrm{Ca}$ & $251 \times 10$ & 914 \\
$\mathrm{Ba}-\mathrm{Mg}$ & $200 \times 10^{3}$ & $834 \times 10^{3}$ \\
$\mathrm{Sr}-\mathrm{Ca}$ & 100 & 5.25 \\
$\mathrm{Sr}-\mathrm{Mg}$ & $795 \times 10^{2}$ & $480 \times 10$ \\
$\mathrm{Ca}-\mathrm{Mg}$ & 795 & 913
\end{tabular}

These values are used for the calculation of separation factors also listed in Table 1. The separation factors for each combination can be written as follows.

$\log \mathrm{Sf}=\mathrm{pH}_{1 / 2(\mathrm{M} 1)}-\mathrm{pH}_{1 / 2(\mathrm{M} 2)}$

where Sf represents separation factor. $\mathrm{pH}_{1 / 2(\mathrm{M} 1)}$ and $\mathrm{pH}_{1 / 2(\mathrm{M} 2)}$ denote the coresponding $\mathrm{pH}_{1 / 2}$ values for metal ions.

It is obvious in Table 1 that the separation factor between $\mathrm{Mg}$ and $\mathrm{Sr}$ by solvent extraction method is large enough to separate each other. The separation factors of $\mathrm{Mg}-\mathrm{Sr}$ and $\mathrm{Sr}-\mathrm{Ba}$ by ion exchange method are also large enough for separation. On the other hand, the values of separation factor between $\mathrm{Ca}-\mathrm{Sr}$ given by solvent extraction and ion exchange methods are too small to separate both ions. 


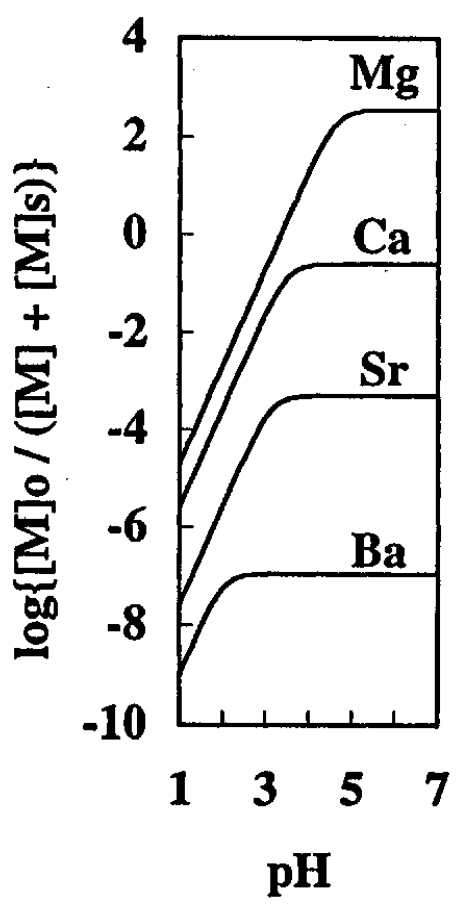

Figure 2 Solvent extraction of alkaline earth metal ions with TTA and TOPO calculated by the data of solvent extraction and ion exchange as a function of $\mathrm{pH}$. The $\log [\mathrm{M}]_{0} /\left([\mathrm{M}]_{\mathrm{aq}}+[\mathrm{M}]_{\mathrm{s}}\right)$ is the distributed metal ratio of alkaline earth metal ions in logarithm given by the triple phase system.

To separate $\mathrm{Ca}^{2+}$ and $\mathrm{Sr}^{2+}$, triple phase separation system was used to partition $\mathrm{Ca}^{2+}$ into the organic phase and $\mathrm{Sr}^{2+}$ onto the ion exchange material. Figure 2 gives the theoretical ratio of extracted alkaline earth metal ions calculated by solvent extraction and ion exchange data. The log $[\mathrm{M}]_{\mathrm{o}} /\left([\mathrm{M}]_{\mathrm{aq}}+[\mathrm{M}]_{\mathrm{s}}\right)$ is the distributed metal ratio of alkaline earth metal ions in logarithm.

As the solvent extraction and ion exchange reactions between hydrogen-ions and alkaline earth metal ions, almost all alkaline earth metal ions stays in an aqueous solution in the lower $\mathrm{pH}$ region. At $\mathrm{pH} 1$, even $\mathrm{Mg}^{2+}$ exists more than $99.99 \%$ in the aqueous solution. The metal ions are extracted into the organic solution in the higher $\mathrm{pH}$ region. From the data in Fig.2, all four curves reach the constant lines in the $\mathrm{pH}$ reagion above 5 . In the plateau region, the differences of the distributed metal ratio for four alkaline earth metal ions are bigger than those given by solvent extraction and ion exchange methods. Even for $\mathrm{Ca}-\mathrm{Sr}$, the separation factor is more than 500 which is large enough to separate each other.

\section{References}

1. Y.Hasegawa, H.Kawashima and T.Sekine, Bull. Chem. Soc. Jpn.,43,1718(1970).

2. Y.Komatsu, Y.Fujiki and T.Sasaki, Solv. Extr. Ion Exch.,9(3), 471(1991).

3. N.S.Poluekotov and S.V.Beltyukova, Zh. Anal. Khim.,25, 2106(1970).

4. E.V.Lapitskaya and F.P.Gorbenko, Radiokhimiya, 10.90 (1967).

5. M.Abe, R.Chitrakar, M.Tsuji and K.Fujimoto, Solv. Extr. Ion Exch.,3(1), 149(1985).

6. H.Sekino and I.Tomita, Bull. Chem. Soc. Jpn., 46,1005(1973).

7. Y. Komatsu, Y. Fujiki and T. Sasaki, Bunseki Kagaku E33,32(1986).

8. Y. Fujiki and N. Ohta, Yogyo-Kyokai-Shi, 88,111(1980). 